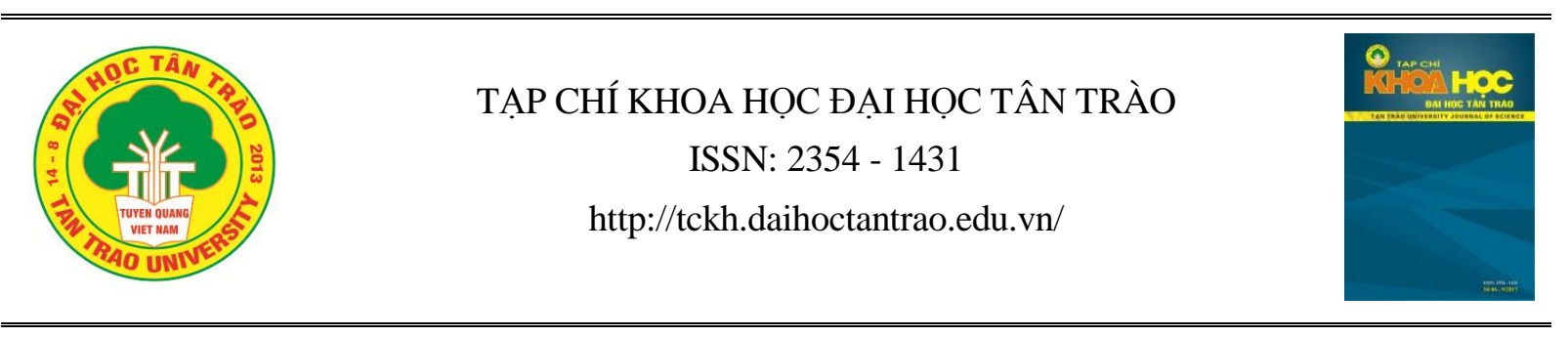

\title{
NGHIÊN CÚU CÁC YẾU TỐ ẢNH HƯởNG ĐẾN QUÁ TRÌNH TÁCH CHIẾT SAPONIN TỬ HẠT CHÔM CHÔM
}

\author{
Nguyễn Văn Bình ${ }^{a}$, Phạm Thị Phuoong ${ }^{a^{*}}$ \\ ${ }^{a}$ Truò̀ng ĐH Nông Lâm Thái Nguyên \\ *Email: phamthiphuong@tuaf.edu.vn
}

\section{Thông tin bài viết}

\section{Ngày nhận bài:}

16/7/2020

Ngày duyệt đăng:

$12 / 8 / 2020$

Tù khóa:

Hạt chôm chôm, saponin, trích ly, dung môi, nguyên liệu

\begin{abstract}
Tóm tắt
Mục tiêu của nghiên cứu này là nghiên cứu khảo sát một số yếu tố ảnh hưởng đến quá trình tách chiết saponin từ hạt chôm chôm bao gồm: kích thước nguyên liệu, nồng độ dung môi (ethanol), tỷ lệ nguyên liệu/ dung môi và thời gian tách chiết. Hạt chôm chôm được mua từ chợ Túc Duyên Thành phố Thái Nguyên. Hạt sau khi được tách ra khỏi thịt quả được bóc vỏ và làm khô đến độ ẩm khoảng $8 \%$ để dùng cho các thí nghiệm. Kết quả cho thấy kích thước nguyên liệu phù hợp là $1,2 \mathrm{~mm}$, nồng độ dung môi trích ly tốt nhất là $70 \%$, tỷ lệ dung môi chiết là: $250 \mathrm{ml} / 5 \mathrm{~g}$ nguyên liệu và thời gian trích ly là 3 giờ cho hiệu quả chiết saponin cao nhất.
\end{abstract}

\section{MỞ ĐẦU}

Saponin hay saponin glycoside là những hoạt chất sinh học quan trọng thuộc nhóm glycoside, thường gặp trong giới thực vật [6]. Saponin được chú ý rất nhiều bởi các nhà khoa học trên toàn thế giới, bởi cấu trúc đặc biệt của nó và tác dụng sinh học đa dạng. Nhiều tác dụng sinh học đáng chú ý từ dịch chiết, từ các nhóm hoạt chất hay hoạt chất tinh khiết đã được chứng minh như hạ đường huyết, hạ cholesrerol, tăng cường miễn dịch [8], chống viêm, chống mệt mỏi, chống ung thư, chống oxy hóa [1], kháng nấm, kháng khuẩn [5]. Bên cạnh đó saponin còn được sử dụng như một điểm khởi đầu cho việc bán tổng hợp các thuốc steroid trong ngành dược phẩm. Sheng and Sun (2011) đã xem xét ý nghĩa lâm sàng của saponin triterpene trong phòng ngừa và điều trị bệnh chuyển hóa và mạch máu [4]. Mặt khác, saponin cũng thường được sử dụng làm chất nhũ hóa hay chất ổn định bề mặt trong các lĩnh vực thực phẩm và mỹ phẩm do có khả năng hoạt động bề mặt rất mạnh nhờ vào cấu trúc của chúng gồm 2 phần: phân cực (đường) và không phân cực (aglycon) [2].

Hiện nay, việc tái sử dụng hay tận dụng giá trị của các sản phẩm phụ từ quá trình sản xuất nông nghiệp đang được các nhà khoa học trên thế giới rất quan tâm. Ở nước ta, chôm chôm Thái hay chôm chôm Rong Rieng (Nephelium lappaceum L.), thuộc họ bồ hòn (Sapindaceae) được trồng rất phổ biến để lấy quả cung cấp cho ngành công nghiệp sản xuất và chế biến hoa quả, đồ uống... Giống chôm chôm này được du nhập từ Thái Lan về trồng ở Việt Nam và thích nghi tốt với điều kiện khí hậu, đất đai của nhiều vùng miền ở nước ta, đặc biệt là vùng Đông Nam Bộ và Đồng Bằng Sông Cửu Long [7]. Sau quá trình sản xuất, hạt và vỏ quả thường được coi là những sản phẩm phụ vô giá trị và bị loại bỏ. Tuy nhiên, nhiều nghiên cứu đã cho thấy, hạt chôm chôm có chứa saponin và nhiều 
hợp chất có hoạt tính sinh học có giá trị khác [2]. Với một lượng lớn các sản phẩm phụ này, có thể tận dụng để chiết xuất lấy saponin như một nguồn saponin tự nhiên sử dụng trong các ngành công nhiệp thực phẩm, mỹ phẩm và dược phẩm. Do đó việc lựa chọn chính xác kỹ thuật chiết xuất thông qua đánh giá các yếu tố ảnh hưởng đến quá trình tách chiết saponin là rất cần thiết.

\section{VẠT LIỆU VÀ PHƯƠNG PHÁP NGHIÊN CÚU}

\subsection{Vật liệu nghiên cứu}

Chôm chôm được thu mua tại chợ Túc Duyên, TP Thái Nguyên, Thái Nguyên. Chuẩn bị mẫu: Hạt chôm chôm được rửa sạch, sau đó, nhân hạt được tách khỏi vỏ hạt. Nhân hạt được làm khô đến độ ẩm khoảng $8 \%$ và bảo quản trong tủ đông cho các thí nghiệm tiếp theo.

\subsection{Phương pháp bố trí thí nghiệm.}

2.2.1. Nghiên cứu ảnh hưởng của kích thước nguyên liệu

Nguyên liệu được nghiền thành bột với các kích thước 0,8 mm, 1,2 mm, 1,6 mm. 5 g nguyên liệu được cho vào bình tam giác với $150 \mathrm{ml}$ ethanol 70\%. Bình tam giác được bọc kín bằng giấy bạc để tránh sự hao hụt dung môi. Quá trình trích ly saponin thô được thực hiện trong thời gian 3 giờ. Sau quá trình trích ly, phần rắn được loại bỏ, dịch chiết thu được bằng cách lọc chân không. Tiếp theo đó, dung môi được loại bỏ và thu được saponin thô. Saponin thô được bảo quản trong tủ lạnh để phân tích hàm lượng saponin. Ethanol được lựa chọn làm dung môi trong tách chiết saponin vì ethanol và methanol là hai dung môi thường được sử dụng để chiết saopnin từ nguyên liệu thưc vật tuy nhiên ethanol được sử dụng phổ biến hơn do ethanol được cho là ít độc và thân thiện với môi trường hơn methanol [2]

\subsubsection{Nghiên cứu ảnh hưởng của nồng độ ethanol}

Nguyên liệu được nghiền thành bột với kích thước theo thí nghiệm 2.2.1. 1,5 g nguyên liệu được cho vào bình tam giác với $150 \mathrm{ml}$ ethanol ethanol ở các nồng độ dung môi 50, 60, 70, 80\%. Bình tam giác được bọc kín bằng giấy bạc để tránh sự hao hụt dung môi. Quá trình trích ly saponin thô được thực hiện trong thời gian 3 giờ. Sau quá trình trích $1 \mathrm{y}$, phần rắn được loại bỏ, dịch chiết thu được bằng cách lọc chân không. Tiếp theo đó, dung môi được loại bỏ và thu được saponin thô. Saponin thô được bảo quản trong tủ lạnh để phân tích hàm lượng saponin.

2.2.3.Nghiên cứu ảnh hưởng của tỉ lệ nguyên liệu/dung môi:

Nguyên liệu được nghiền thành bột với kích thước được đánh giá là tốt nhất theo thí nghiệm 2.2.1. 1,5 g nguyên liệu được cho vào bình tam giác với $150 \mathrm{ml}$, $250 \mathrm{ml}$ và $350 \mathrm{ml}$ ethanol ở nồng độ tốt nhất theo thí nghiệm 2.2.2. Bình tam giác được bọc kín bằng giấy bạc để tránh sự hao hụt dung môi. Quá trình trích ly saponin thô được thực hiện trong thời gian 3 giờ. Sau quá trình trích ly, phần rắn được loại bỏ, dịch chiết thu được bằng cách lọc chân không. Tiếp theo đó, dung môi được loại bỏ và thu được saponin thô. Saponin thô được bảo quản trong tủ lạnh để phân tích hàm lượng saponin.

\subsubsection{Nghiên cứu ảnh hưởng của thời gian:}

Nguyên liệu được nghiền thành bột với kích thước tốt nhất theo thí nghiệm 2.2.1. 1,5 g nguyên liệu được cho vào bình tam giác với $150 \mathrm{ml}$ ethanol ở nồng độ theo thí nghiệm 2.2.2. Bình tam giác được bọc kín bằng giấy bạc để tránh sự hao hụt dung môi. Quá trình trích ly saponin thô được thực hiện trong thời gian 1 giờ, 3 giờ và 5 giờ. Sau quá trình trích $1 \mathrm{y}$, phần rắn được loại bỏ, dịch chiết thu được bằng cách lọc chân không. Tiếp theo đó, dung môi được loại bỏ và thu được saponin thô. Saponin thô được bảo quản trong tủ lạnh để phân tích hàm lượng saponin.

\subsection{Phương pháp xác định hàm lượng saponin.}

Hàm lượng saponin được xác định bằng phương pháp đo màu theo phương pháp của Goel et al. (2012) [3] với một số thay đổi. Chiết xuất thô $(10 \mathrm{mg})$ được hòa tan trong nước cất $(5 \mathrm{ml})$ và sau đó dung dịch $(0,5 \mathrm{ml})$ được cho vào các ống nghiệm với thuốc thử vanillin $(0,5 \mathrm{ml})(8 \% \mathrm{w} / \mathrm{v}$ trong $99,9 \%$ ethanol). Các ống mẫu được đặt trong bể nước đá lạnh và sau đó, acid sulfuric $(5 \mathrm{ml}) 72 \%(\mathrm{v} / \mathrm{v})$ được thêm từ từ vào. Sau khi lắc, các ống mẫu được để yên (3 phút) trong bể nước đá lạnh. Tiếp theo, các ống mẫu được làm nóng đến $60^{\circ} \mathrm{C}$ trong bể ổn nhiệt và để yên trong 10 phút, sau đó, được làm mát đến nhiệt độ phòng. Độ hấp thụ được đo ở bước sóng $544 \mathrm{~nm}$ sử dụng máy quang phổ (G10S UV-VIS, Thermo Fisher Scientific Inc., USA). Mẫu đối chứng được chuẩn bị bằng nước cất thay vì mẫu chiết thô. Đường cong chuẩn được chuẩn bị bằng cách sử dụng Quillaja saponin $(\mathrm{QS})$ và 
hàm hượng saponin được biểu thị qua hàm lượng $\mathrm{QS}$ (mg QS/g chiết xuất thô).

\subsection{Phương pháp xử lý số liệu.}

Thí nghiệm được bố trí là thí ngiệm đơn nhân tố, mối thí nghiệm được lặp lại 3 lần, số liệu nghiên cứu được xử lý bằng phần mềm SPSS phiên bản 20. Sự sai khác giữa các giá trị trung bình của các công thức được đánh giá bằng so sánh Duncan.

\section{KẾT QUẢ VÀ THẢO LUẬN}

3.1. Kết quả nghiên cứu ảnh hưởng của kích thước nguyên liệu

Kích thước nguyên liệu là một trong những yếu tố quan trọng ảnh hưởng đến hiệu suất trích ly các chất trong hạt chôm chôm. Bình thường các hợp chất được giữ trong tế bào, chúng rất khó được tách ra nếu không có tác động của các yếu tố bên ngoài. Việc cắt nhỏ nguyên liệu có tác dụng làm cho tế bào bị phá vỡ, từ đó giải phóng các chất, tạo điều kiện cho quá trình trích ly dễ dàng và triệt để hơn. Kết quả nghiên cứu ảnh hưởng của kích thước nguyên liệu đến hiệu suất trích ly saponin thô trong hạt chôm chôm được thể hiện trong Bảng 3.1.

Bảng 3.1 Ảnh hưởng của kích thước nguyên liệu đến hàm lượng saponin

\begin{tabular}{|l|l|l|}
\hline \multicolumn{1}{|c|}{ CT } & $\begin{array}{c}\text { Kích thước } \\
(\mathbf{m m})\end{array}$ & \multicolumn{1}{|c|}{$\begin{array}{c}\text { Hàm lượng saponin } \\
(\mathrm{mg} \text { QS/g dịch chiết thô })\end{array}$} \\
\hline CT1 & 0,8 & $455,67^{\mathrm{a}}$ \\
\hline CT2 & 1,2 & $453,67^{\mathrm{a}}$ \\
\hline CT3 & 1,6 & $447,67^{\mathrm{b}}$ \\
\hline
\end{tabular}

(Ghi chú: Các chũ số ở cùng một cột có số mũ khác nhau thì khác nhau có ý nghĩa ở mức $\alpha=0,05)$

Từ kết quả nghiên cứu ở Bảng 3.1 ta thấy kích thước của nguyên liệu càng lớn thì hàm lượng saponin thu được càng thấp, nguyên liệu càng nhỏ thì hiệu suất trích ly, hàm lượng saponin càng cao. Nguyên liệu có kích thước $\mathrm{d}=0,8 \mathrm{~mm}$ cho hàm lượng saponin cao nhất đạt giá trị 455,67mg/g hiệu suất trích ly của quá trình đạt 78,18\%. Nguyên liệu ở kích thước 1,2 mm cho hàm lượng saponin đạt 453,67 mg/g. Nguyên liệu ở kích thước $\mathrm{d}=1,6 \mathrm{~mm}$ cho hiệu suất thấp nhất, hàm lượng saponin chỉ đạt 447,67 mg/g, so với ở kích thước $\mathrm{d}=0,8 \mathrm{~mm}$ thì hàm lượng saponin thu được thấp hơn $8 \mathrm{mg} / \mathrm{g}$. Ở kích thước lớn thì mức độ phá vỡ tế bào của nguyên liệu thấp, dẫn đến dung môi khó thấm sâu vào bên trong nguyên liệu làm cho hiệu quả trích ly thấp. Nguyên liệu có kích thước nhỏ dung môi dễ dàng thấm sâu vào trong tế bào nguyên liệu giúp giải phóng các chất hòa tan trong tế bào nguyên liệu ra ngoài, dẫn đến hiệu quả trích ly cao. Tuy nhiên dựa vào Bảng 3.1 ta thấy rằng ở hàm lượng saponin ở kích thước $\mathrm{d}=0,8 \mathrm{~mm}$ và $\mathrm{d}=1,2 \mathrm{~mm}$ không có sự sai khác. Vậy nên để tối ưu quá trình trích ly cũng như tiết kiệm thời gian và năng lượng để nghiền nhỏ nguyên liệu và dễ dàng hơn cho quá trình lọc dịch trích ly, chúng tôi lựa chọn nguyên liệu ở kích thước $\mathrm{d}=1,2 \mathrm{~mm}$ cho các thí nghiệm sau.

\subsection{Kết quả nghiên cứu ảnh hưởng của nồng độ}

\section{dung môi}

Để đánh giá ảnh hưởng của nồng độ dung môi đến quá trình trích ly hợp chất saponin trong hạt chôm chôm, chúng tôi tiến hành thí nghiệm lần lượt ở nồng độ dung môi khác nhau: 50\%, 60\%, 70\%, 80\%. Kết quả nghiên cứu được thể hiện Bảng 3.2

Bảng 3.2 : Kết quả nghiên cứu ảnh hưởng của nồng độ ethanol đến quá trình trích ly hợp chất saponin từ hạt chôm chôm

\begin{tabular}{|c|c|c|}
\hline CT & $\begin{array}{c}\text { Nồng độ } \\
\text { ethanol (\%) }\end{array}$ & $\begin{array}{c}\text { Hàm lưộng saponin } \\
\text { (mg QS/g dịch chiết thô) }\end{array}$ \\
\hline CT1 & 50 & $441,33^{\mathrm{ab}}$ \\
\hline CT2 & 60 & $444,67^{b}$ \\
\hline CT3 & 70 & $454,33^{\mathrm{a}}$ \\
\hline CT4 & 80 & $437,33^{\mathrm{c}}$ \\
\hline
\end{tabular}

(Ghi chú: Các chũ số ở cùng một cột có số mũ khác nhau thì khác nhau có ý nghĩa ở múc $\alpha=0,05)$

Từ Bảng 3.2 ta thấy hàm lượng saponin tổng trong dịch chiết tăng lên rõ theo nồng độ dung môi từ 50 đến $70 \%$. Hàm lượng saponin cao nhất thu được ở nồng độ ethanol $70 \%$ là 454,33 mg/g, khi nồng độ ethanol tăng lên trên $70 \%$ hàm lượng saponin giảm mạnh là 437,33mg/g, cho thấy nồng độ ethanol cao không thích hợp để chiết các hợp chất saponin từ hạt chôm chôm. Kết quả chỉ ra nồng độ ethanol $70 \%$ là thích hợp nhất để chiết xuất saponin. Nên lựa chọn nồng độ dung môi là $70 \%$ cho thí nghiệm tiếp theo.

\subsection{Kết quả nghiên cứu ảnh hưởng của tỉ lệ nguyên liệu/dung môi}

Lượng dung môi nhiều hay ít đều ảnh hưởng tới quá trình chiết tách các hợp chất trong nguyên liệu. Nếu lượng dung môi quá ít thì chỉ đủ để thấm ướt nguyên liệu vì vậy hiệu suất trích ly sẽ thấp. Ngược lại, nếu lượng dung môi quá nhiều thì gây hao phí 
dung môi, nhiên liệu và các chi phí khác. Vì vậy việc tìm ra tỷ lệ nguyên liệu/dung môi là rất cần thiết cho quá trình trích ly. Kết quả nghiên cứu ảnh hưởng của tỷ lệ nguyên liệu/dung môi được thể hiện ở Bảng 3.3.

Bảng 3.3 Kết quả nghiên cứu ảnh hưởng của tỷ lệ nguyên liệu/dung môi đến hiệu quả trích ly Saponin trong hạt chôm chôm

\begin{tabular}{|l|l|l|}
\hline \multicolumn{1}{|c|}{ CT } & $\begin{array}{c}\text { Lượng dung } \\
\text { môi (ml) }\end{array}$ & $\begin{array}{c}\text { Hàm lượng saponin } \\
(\mathrm{mg} \text { QS/g dịch chiết thô })\end{array}$ \\
\hline CT1 & 150 & $454,33^{\mathrm{b}}$ \\
\hline CT2 & 250 & $462,33^{\mathrm{a}}$ \\
\hline CT3 & 350 & $466,67^{\mathrm{a}}$ \\
\hline
\end{tabular}

(Ghi chú: Các chũ số ở cùng một cột có số mũ khác nhau thì khác nhau có ý nghĩa ở mức $\alpha=0,05$ )

Từ Bảng 3.3 cho thấy tỷ lệ nguyên liệu/dung môi càng nhỏ thì hàm lượng saponin thu được càng lớn. Nguyên liệu được trích ly bằng dung môi là cồn $70 \%$ với lượng dung môi là $350 \mathrm{ml}$ cho hàm lượng saponin thu được cao nhất đạt 466,67mg/g, với lượng dung môi là $250 \mathrm{ml}$ thu được hàm lượng saponin thô đạt $462,33 \mathrm{mg} / \mathrm{g}$, lượng dung môi $150 \mathrm{ml}$ thu được hàm lượng saponin thô đạt $454,33 \mathrm{mg} / \mathrm{g}$. Tuy nhiên ở giới hạn nhất định nếu tiếp tục tăng lượng dung môi vào quá trình trích ly hàm lượng saponin thu được có tăng nhưng rất ít và không có sự khác biệt ở CT2 và CT3. Khi sử dụng lượng dung môi $350 \mathrm{ml}$ sẽ gây tốn kém về kinh tế và khó khăn cho quá trình lọc về sau mà hàm lượng saponin thu được rất nhỏ, không đáng kể do được trích ly gần như hoàn toàn với lượng dung môi $250 \mathrm{ml}$. Để đảm bảo hiệu suất của quá trình trích ly cũng như tối thiểu các chi phí (nguyên liệu, năng lượng...) chúng tôi lựa chọn ở tỷ lệ dung môi là 250ml làm kết quả cho các thí nghiệm tiếp theo.

\subsection{Kết quả nghiên cứu ảnh hưởng của thời gian.}

Thời gian trích ly có ảnh hưởng lớn đến hiệu suất thu hồi hợp chất Saponin trong hạt chôm chôm, nếu thời gian trích ly ngắn làm cho hợp chất saponin không đủ thời gian hòa tan trong dung môi trích, làm hợp chất saponin trong bã trích ly còn cao, làm tổn thất lớn trong quá trình tách chiết. Do vậy chúng tôi tiến hành thí nghiệm với sự thay đổi thời gian chiết lần lượt là 1 giờ, 3 giờ, 5 giờ. Kết quả thí nghiệm được trình bày ở Bảng 3.4
Bảng 3.4 Kết quả nghiên cứu ảnh hưởng của thời gian trích ly đến hiệu quả trích ly saponin trong hạt chôm chôm

\begin{tabular}{|l|l|l|}
\hline CT & \multicolumn{1}{|c|}{$\begin{array}{c}\text { Thò̀i gian } \\
\text { (giờ) }\end{array}$} & \multicolumn{1}{c|}{$\begin{array}{c}\text { Hàm lưọng saponin } \\
(\mathrm{mg} \text { QS/g dịch chiết thô) }\end{array}$} \\
\hline CT1 & 1 & $410,00^{\mathrm{b}}$ \\
\hline CT2 & 3 & $462,00^{\mathrm{a}}$ \\
\hline CT3 & 5 & $466,67^{\mathrm{a}}$ \\
\hline
\end{tabular}

(Ghi chú: Các chũ số ở cùng một cột có số mũ khác nhau thì khác nhau có ý nghĩa ở mức $\alpha=0,05$ )

Kết quả Bảng 3.4 cho thấy thời gian trích ly càng dài thì hàm lượng saponin thu được càng cao. Tuy nhiên đến một thời gian trích ly nhất định thì lượng hoạt chất tăng lên rất chậm hoặc không tăng nữa. Khi trích ly ở thời gian 1 giờ thì hàm lượng saponin thu được thấp, chỉ đạt $410,00 \mathrm{mg} / \mathrm{g}$. Hàm lượng saponin tăng nhanh khi trích ly ở thời gian 3 giờ, với hàm lượng saponin thu được 462,00mg/g. Sau 5 giờ trích ly, lượng saponin thu được là 466,67mg/, hàm lượng saponin có tăng nhưng không có sự chênh lệch so với trích ly ở 3 giờ. Do vậy nếu trích ly trong 5 giờ thì mất nhiều thời gian thực hiện và hàm lượng saponin thu được không khác nhiều so với trích ly ở 3 giờ. Do đó chúng tôi chọn thời gian trích ly là 3 giờ cho hàm lượng saponin là 462,00mg/g

\section{KẾT LUẦN}

Kết quả nghiên cứu một số yếu tố ảnh hưởng đến quá trình tách chiết saponin trong hạt chôm chôm cho thấy hiệu xuất trích ly saponin từ hạt chôm chôm tăng khi kích thước nguyên liệu giảm, kích thước nguyên liệu là $1,2 \mathrm{~mm}$ cho hàm lượng saponin cao nhất là 453,67 mgQs/g dịch chiết thô, nồng độ ethanol thích hợp để tách chiết các hợp chất saponin từ hạt chôm chôm là $70 \%$ thu được hàm lượng saponin tương ứng là $54,33 \mathrm{mg} / \mathrm{g}$, tỷ lệ dung môi chiết là $250 \mathrm{ml} / 5 \mathrm{~g}$ nguyên liệu thu được hàm lượng saponin thô đạt $462,33 \mathrm{mg} / \mathrm{g}$, và thời gian trích ly là 3 giờ cho hàm lượng saponin cao nhất là $462 \mathrm{mgQs} / \mathrm{g}$.

\section{TÀI LIẸU THAM KHẢO}

1. Chan, K. W., Khong, N. M. H., Iqbal, S., \& Ismail, M. (2013). Isolation and antioxidative properties of phenolics-saponins rich fraction from defatted rice bran. Journal of Cereal Science, 57, pp. 480-485

2. Cheok, C.Y., H.A.K. Salman and R. Sulaiman. 
2014, Extraction and quantification of saponins: a review. Food Research International 59: pp. 16-40.

3. Goel, N., Sirohi, S. K., \& Dwivedi, J, (2012), Estimation of total saponins and evaluate their effect on in vitro methanogenesis and rumen fermentation pattern in wheat straw based diet, Journal of Advanced Veterinary Research, 2, 120-126

4. Sheng, H., \& Sun, H. (2011), Synthesis, biology and clinical significance of pentacyclic triterpenes: A multi-target approach to prevention and treatment of metabolic and vascular diseases, Natural Product Reports, 28, pp. 543-593.

5. Sparg, S. G., Light, M. E., \& van Staden, J, (2004), Biological activities and distribution of plant saponins, Journal of Ethnopharmacology, 94, pp. 219-243

6. Tran Van Hau and Chau Trung Duong (2006). Some biological characteristics of the flowering of the
Javan tree rambutans are cultivated in Can Tho. Journal of Scientific Research Can Tho University ( vol.6): p. 53-59.

7. Nguyen Minh Thuy, Nguyen Thi Thu Hong, Nguyen Phu Cuong, Nguyen Thi My Tuyen, Duong Kim Thanh1 and Ho Thanh Huong (2013), Changing the physical, chemical properties and sensory properties of the Java rambutan tree din the process of domestication and storage. Scientific Journal of Can Tho University (vol. 28): p. 28 -35.

8. Verza, S. G., Silveira, F., Cibulski, S., Kaiser, S., Ferreira, F., Gosmann, (2012), Immunoadjuvant activity, toxicity assays, and determination by UPLC/Q-TOF-MS of triterpenic saponins from Chenopodium quinoa seeds. Journal of Agricultural and Food Chemistry, 60, pp. 3113-311

\section{Study on the factors effecting the extraction of Saponin from rambutan seeds}

Nguyen Van Binh, Pham Thi Phuong

\begin{tabular}{l}
\hline Article info \\
\hline Recieved: \\
16/7/2020 \\
Accepted: \\
12/8/2020 \\
\hline
\end{tabular}

Keywords:

Rambutan seed, saponin, extraction, solvent, material.

\begin{abstract}
The purpose of this research was to analyze the factors affecting the extraction of saponin from rambutan seeds, such as material size, solvent concentration (ethanol), material / solvent ratio and extraction time. Rambutan seeds were purchased from Tuc Duyen market in Thai Nguyen City. The seeds were separated from the pulp then dried to a moisture content of about $8 \%$ to use for experiments. The results showed that the suitable material size was $1.2 \mathrm{~mm}$, the best extraction ethanol concentration was $70 \%$, the extraction solvent rate was: $250 \mathrm{ml} / 5 \mathrm{~g}$ of raw material and the extraction time was 3 hours for the highest saponin.
\end{abstract}

